Rev Bras P siquiatr 2002;24(4):162-3

\title{
Editorial
}

(autores convidados)

\section{Dados epidemiológicos em psiquiatria infantil: orientando políticas de saúde mental}

A informação epidemiológica pode ser utilizada com finalidade científica e administrativa. Do ponto de vista científico, o epidemiologista preocupa-se com diferenças entre taxas de transtornos em diferentes grupos. A comparação de tais taxas pode ser essencial para responder a perguntas sobre o papel causal de supostos fatores de risco na origem de um transtorno. ${ }^{1}$ De uma perspectiva administrativa, achados epidemiológicos são também de grande importância, pois fornecem informações para planejamento. Dados referentes a uma determinada área geográfica constituem evidência confiável a agências governamentais e a provedores de saúde mental sobre a natureza e magnitude de um problema e as verdadeiras necessidades da população local.

A identificação de problemas psiquiátricos em crianças e adolescentes coloca desafios que vão além daqueles presentes na identificação de transtornos mentais em adultos. Como a criança encontra-se em um período do desenvolvimento, no qual sua capacidade de atribuir o desconforto que experimenta a uma fonte interna é limitada, seus problemas emocionais tendem a expressar-se por meio de comportamentos desadaptados e desviantes, raramente associados pela própria criança a um sofrimento interno. Um diagnóstico competente nesse grupo etário demanda procedimentos de avaliação cuidadosos e abrangentes, bem como a recorrência a fontes de informação diversas, como professores, pais, pediatras, registros escolares e outros.

A avaliação epidemiológica da população infantil e de adolescentes é, portanto, complexa e dispendiosa. A aplicação de medidas padronizadas, culturalmente adequadas, e a utilização de múltiplos informantes são elementos necessários para que possa ser efetuada a avaliação de estados psicopatológicos, supostos fatores de risco, prejuízo funcional, demanda de serviços de saúde mental e barreiras para a utilização desses serviços.

A capacidade do adulto de identificar problemas de saúde mental em si próprio e nas crianças por quem é responsável, bem como a capacidade de encaminhá-las para tratamento, está diretamente ligada ao acesso à informação sobre o tema e à disponibilidade de recursos de tratamento. Esse fato dá origem a uma questão, mais evidente em países em desenvolvimento, embora pertinente em todo o mundo: se as pessoas não estão cientes de uma necessidade, esta realmente existe? Serviços devem ser criados e planejados para atender a necessidades que não são expressas por aqueles que supostamente necessitam desses serviços? Parte da resposta é que tais esforços de avaliação e planejamento devem ocorrer em conjunto com programas educacionais que ampliem a consciência e o conhecimento da população. Mas, faz sentido educar a população para detectar condições quando não se dispõe de recursos para atender às necessidades que serão identificadas? Nesse caso, o esforço deve ser dirigido para o incremento da capacidade de formular intervenções amplamente aplicáveis, culturalmente adaptadas e com relação custo-benefício positiva.

A informação sistemática pode servir como poderosa ferramenta para exercer uma pressão política significativa, levando à formulação de leis e decisões que podem levar à idealização de um programa coerente e efetivo de atenção à saúde mental infantil. Ilustramos abaixo como dados epidemiológicos locais sobre transtornos mentais em crianças e adolescentes podem ser críticos para que se priorizem escolhas em uma área no campo da saúde anteriormente ignorada, mesmo que os dados obtidos não revelem nenhuma informação realmente nova sobre problemas mentais em crianças e adolescentes.

Bird et $\mathrm{al}^{2}$ conduziram um estudo em Porto Rico em 1985, o qual, depois de ter seus resultados disseminados, aumentou significativamente o orçamento destinado a serviços de saúde mental infantil. Tal incremento no financiamento gerou melhoria da qualidade e aumento na utilização dos serviços de saúde mental na ilha. Cinco anos depois de os dados do estudo de 1985 terem sido disponibilizados e amplamente divulgados não apenas em jornais científicos mas também na imprensa local, o orçamento governamental anual destinado à saúde mental infantil aumentou dez vezes, e foi criada a primeira unidade de internação psiquiátrica infantil em instituição pública. Dados do estudo geraram não apenas estimativas de taxas gerais de transtornos e de supostos fatores de risco na população mas também taxas de utilização e demanda de serviços por parte da população, bem como a identificação de barreiras econômicas e geográficas, entre outras, que impossibilitavam aqueles que percebiam a necessidade de atenção de realmente obter atendimento. ${ }^{3}$ Finalmente, os dados também forneceram informações sobre os tipos de serviços necessários e as localidades em que os serviços eram escassos ou inexistentes. 
Outro exemplo, mais recente, de dados epidemiológicos despertando atenção sobre as necessidades de crianças e adolescentes na área de saúde mental é o estudo da Secretaria de Educação da cidade de Nova York sobre o impacto dos ataques ao World Trade Center na saúde mental infantil. ${ }^{4}$ Em uma amostra probabilística de estudantes de escolas públicas de Nova York, um número acima do esperado de crianças provenientes de escolas de diferentes partes da cidade obteve resultado positivo em rastreamento de oito transtornos mentais. O estudo claramente revelou a necessidade de serviços outros que não apenas para o transtorno de estresse pós-traumático e demonstrou que a necessidade de serviços não se restringia à área próxima ao desastre. Atualmente, essa Secretaria de Educação desenvolve um modelo de atenção para o próximo ano escolar com base nos resultados do estudo. Ainda mais recentemente, os resultados desse estudo estimularam uma discussão nos níveis de governo municipal, estadual e federal sobre o planejamento de financiamento para atender à demanda identificada na área de saúde mental infantil. Em resposta direta aos achados do estudo, a senadora Hillary Clinton convocou uma audição senatorial na cidade de Nova York para obter informações

\section{Referências}

1. Costello EJ, Angold A. Developmental epidemiology. In: Cicchetti D, Cohen D. Manual of developmental pathology. New York: Wiley; 1994.

2. Bird H, Canino G, Rubio-Stipec M, Gould MS, Ribera J, Sesman M, et al. Estimates of the prevalence of childhood maladjustment in a community survey in Puerto Rico: the use of combined measures. Arch Gen Psychiatr 1988;45:1120-6. sobre as melhores estratégias de resposta no nível federal.

Está clara, portanto, a necessidade e efetividade de estudos epidemiológicos planejados para examinar problemas locais de saúde mental na população de crianças e adolescentes. Embora os governos possam muitas vezes indicar que recursos financeiros a ser alocados para uma finalidade específica não estão disponíveis, esse fato geralmente significa que não se está dando devida prioridade às alocações requeridas. Informação sobre a população infantil constitui o melhor meio de estabelecer tais prioridades. Tais dados são o primeiro passo, essencial para o planejamento de um programa racional de serviços de atenção à saúde mental para a população infantil.

Hector R Bird

Columbia University, New York

Cristiane S Duarte

Columbia University. Universidade Federal de São Paulo. Escola Paulista de Medicina

3. Staghezza-Jaramillo B, Bird H, Gould MS, Canino G. Mental health service utilization among Puerto Rican children ages 4 through 16. J Child Fam Studies 1995;4(4):399-418.

4. Hoven CW, Duarte CS, Lucas CP, Mandell DJ, Cohen M, Wu P et al. Effects of the world trade center attack on NYC public school students: initial report to the New York City board of education. Applied Research and Consulting, LLC \& Columbia University Mailman School of Public Health \& New York State Psychiatric Institute. New York; 2002. 